\title{
Care of Baby Chicks ${ }^{1}$
}

\section{Christopher DeCubellis ${ }^{2}$}

Each year many people enjoy ordering chicks from a hatchery or purchasing young chicks from a feed store. These chicks are raised primarily for home laying flocks. Some of these chickens are raised for the family table, while others are kept mainly as pets. Whatever purpose the adult chickens serve, special care must be given to young chicks in order for them to survive and grow into healthy adults.

\section{Care of Chicks}

Chicks, or "biddies" are very delicate and need special care in order to survive, grow, and become productive adults. Thinking about what chicks need before they arrive will help ensure a healthy flock of chickens. Chicks need a clean environment that protects them from drafts and keeps them at the proper temperature. Their environment must provide them with constant access to food and water; it should have proper flooring material, and be located in a safe place away from predators. A brooder is usually used to provide all of these necessities for the chick, especially in late winter and early spring when most people obtain chicks and temperatures are still cool.

\section{Brooder Requirements}

Brooders can range from a commercially purchased metal or wire brooder (see figure 1) to a cardboard box equipped to handle chicks. Brooders should keep out drafts, especially for young chicks. They should have side walls or a draft shield at least 12-18" tall to keep the wind off the young birds.

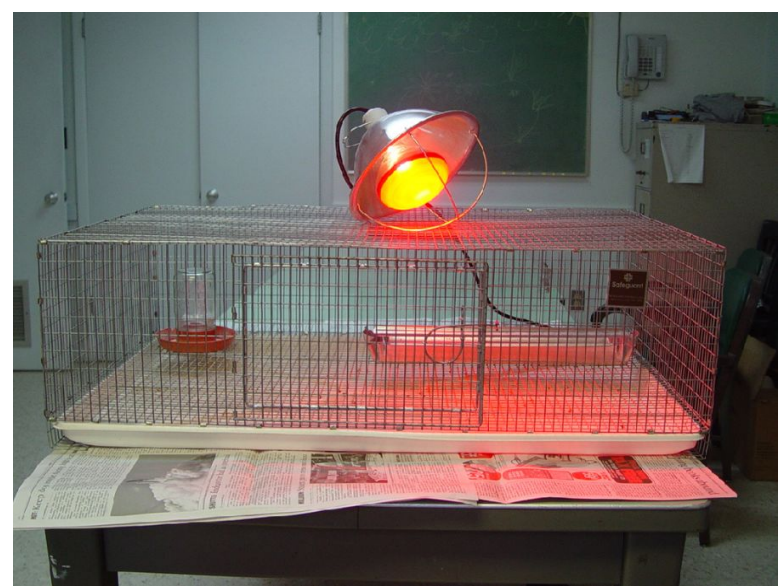

Figure 1. Wire brooder, light on

Brooders should keep chicks at the proper temperature. Newly hatched chicks need to be maintained at 95 degrees Fahrenheit $(F)$ for the first week of their lives. After the first week, chicks can tolerate temperatures 5 degrees $\mathrm{F}$ cooler for each

1. This document is Series AN-170 one of the series of the Animal Science Department, Florida Cooperative Extension Service, Institute of Food and Agricultural Sciences, University of Florida. Publication date: July 2007 Please visit the EDIS Web site at http://edis.ifas.ufl.edu

2. Christopher DeCubellis, Extension Agent 11, 4-H Youth Development, Animal Science Departmant, Gilchrist County Cooperative Extension Service, Institute of Food and Agricultural Sciences, University of Florida, Gainesville 32611

The Institute of Food and Agricultural Sciences (IFAS) is an Equal Opportunity Institution authorized to provide research, educational information and other services only to individuals and institutions that function with non-discrimination with respect to race, creed, color, religion, age, disability, sex, sexual orientation, marital status, national origin, political opinions or affiliations. U.S. Department of Agriculture, Cooperative Extension Service, University of Florida, IFAS, Florida A. \& M. University Cooperative Extension Program, and Boards of County Commissioners Cooperating. Larry Arrington, Dean 
week until they are four weeks old. In other words, one week old chicks can tolerate 90 degrees $\mathrm{F}$ and two week old chicks can tolerate 85 degrees $\mathrm{F}$. The easiest way to heat a homemade brooder is with a light bulb or heat lamp (see figure 2). Suspend the heat source over the middle of the brooder. Observe the chick' behavior to get the brooder temperature right: they will huddle up in the middle directly under the heat source if the brooder is too cold and move to the edge of the brooder away from the heat source if it is too hot. When the brooder is at a comfortable temperature, the chicks will move about freely throughout the available space.

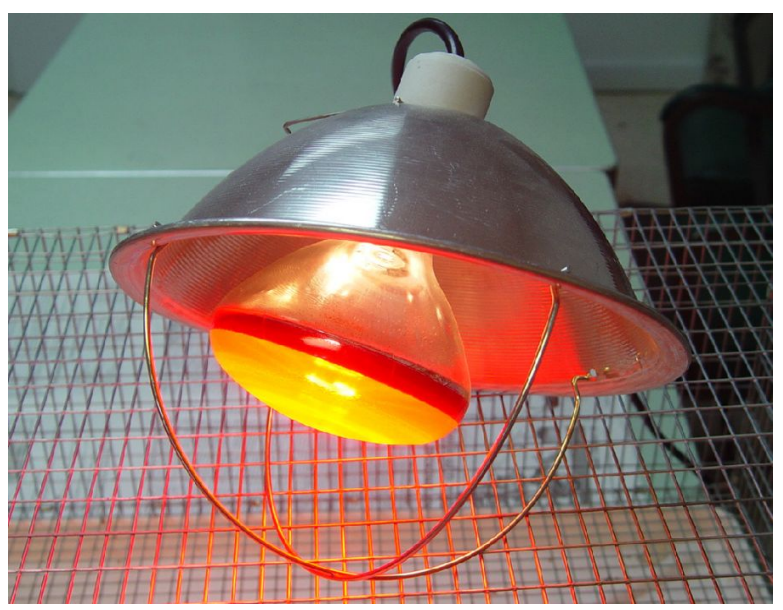

Figure 2. Heat lamp

Whether it is a cardboard box with a light or heat lamp or a commercially purchased model, a brooder has to be able to keep chicks at the proper temperature. Pay careful attention if you are using a cardboard box and heat source to make sure the bulb is at a safe distance from the box so as not to start a fire.

Flooring is important in a brooder to keep the chicks feet and legs healthy. Wire floors are good because they allow waste to drop through. Rice or oat hulls, finely ground corn cob, or wood chips other than cedar make good bedding material. Any shavings need to be at least one to two inches thick. You can start chicks on newspaper for the first day or two and spread their feed on the paper to teach them how to eat. After that, dispose of the newspaper and use some other flooring, as the flat newspaper on a hard surface can cause feet and leg problems later on. Also, newspaper holds moisture and if not removed will cause problems with odors and bacterial growth.

\section{Space Requirements}

Chicks should be able to move about comfortably and have access to feed and water free choice. A good rule of thumb is a half square foot of space for each chick for the first two weeks. Grown chickens need at least 1.5 square feet of floor space in a coop, or about 8 square feet in an outside run or chicken yard. Grown hens need 6-10 inches of roost space each if roosts are used.

\section{When Chicks Arrive}

Chicks can survive up to two or three days without eating or drinking right after hatching because they are able to utilize the nutrients remaining in their retained yolk sac during this time. This is how hatcheries can ship chicks all over the country with little or no mortality. When chicks arrive, they will be thirsty. It is extremely important to make sure each chick gets a good drink of water upon arrival. Water should be available to chicks at all times. It is optional to add $1 / 4$ to $1 / 2$ cup of sugar to one gallon of water to give chicks upon arrival to boost the chicks energy level if they appear lethargic. Also one teaspoon of antibiotic powder specially labeled for chicks and available at most feed stores can be added to water if the chicks appear unthrifty upon arrival. As chicks are removed from the shipping box, dip their beaks in the water to encourage them to drink (see figure 3).

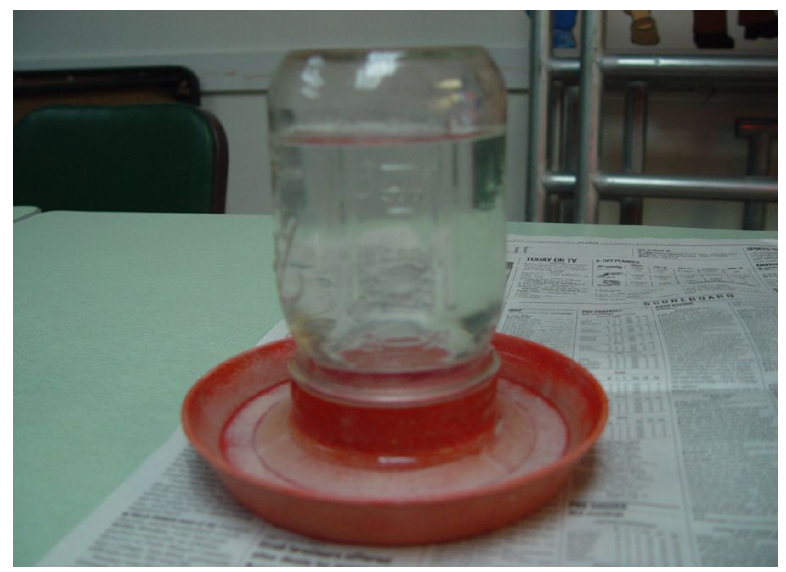

Figure 3. Chick water fount

After each chick has taken a drink, introduce feed. One method is to scatter chick starter on newspaper to encourage chicks to peck at it. In 
addition fine grit can be added to the feed in a 1:10 ratio.

Watch the chicks carefully for about an hour to be sure they are finding water and beginning to eat. Notice how the chicks are reacting to the heat source. Adjust the light or heat source accordingly. To prevent chicks from pecking each other some people use a red light bulb, available at most feed stores.

\section{Feeding Chicks}

The easiest way to feed chicks is to provide them with a pre-mixed commercial chick-starter, available at any feed store, which should be about $20 \%$ crude protein. These feeds are usually medicated. Do not feed three-grain scratch or ground corn. Chicks need more protein, vitamins, and minerals than these feeds can provide. Feed a good commercial chick starter for the first 6-8 weeks. Then switch to a chicken grower feed from 9-20 weeks. At 20 weeks of age switch chickens to a laying feed, such as laying crumbles or mash. Separate roosters and hens at this time if the goal is a home laying flock.

As previously noted, one can start the first meal on newspaper, and once chicks learn to eat, introduce a feeder (see figure 4). Make sure the feeder is large enough that each chick has a place in the "pecking order". Chicks should always have a constant supply of feed and water available to them.

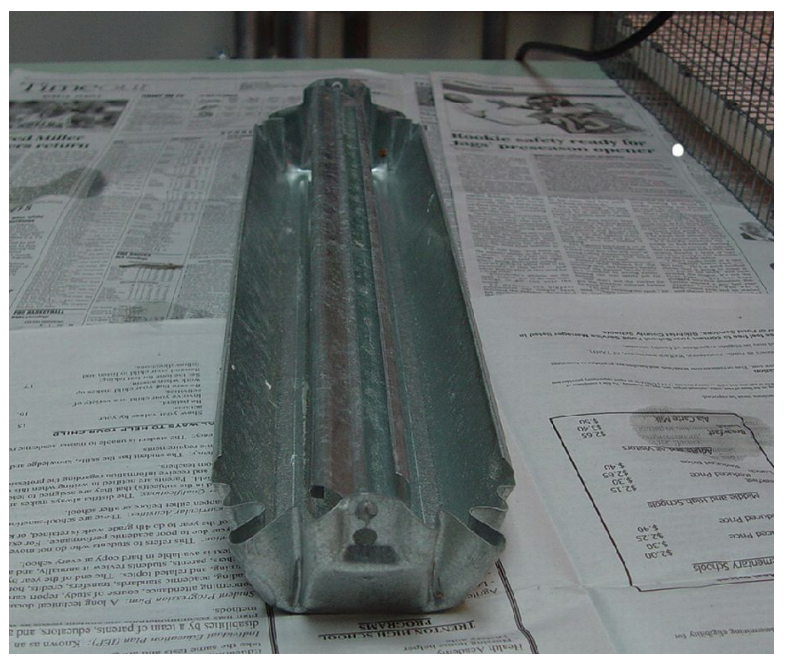

Figure 4. Chick feeder

\section{Keeping Chicks Healthy}

Providing the correct temperature, draft protection, a complete well-balanced feed and clean water will go a long way to keeping chicks healthy. Brooders should be cleaned daily and also kept as dry as possible. Chicks need draft protection, but proper ventilation during the brooding period is very important.

Raising chickens can be an enjoyable way to enjoy ones property, as well as a way to provide eggs and meat for the table. A healthy flock of chickens begins with healthy chicks. If you have any questions about chicken or chicks, please contact your county extension office for more information. 